\title{
O GÊNERO CHARGE NO ENSINO E NA APRENDIZAGEM DE LÍNGUA ESPANHOLA ${ }^{1}$
}

\author{
THE CARTOON DISCURSIVE GENRE IN THE TEACHING AND LEARNING OF THE \\ SPANISH LANGUAGE
}

Simone Beatriz Cordeiro Ribeiro ${ }^{2}$

(UNIOESTE)

simonebcr@yahoo.com.br

Clarice Nadir von Borstel ${ }^{3}$

(UNIOESTE)

clavonborstel@gmail.com

RESUMO: O presente estudo busca, por meio da leitura de uma charge de Martin Favelis, referente às touradas, apresentar uma abordagem pedagógica que envolva, além de uma leitura discursiva da mesma, conteúdos históricos, sociais, culturais e políticos, relativos à língua espanhola. Para tanto, primeiramente, realizou-se uma breve discussão a respeito da trajetória do ensino da língua espanhola no Brasil, a partir dos estudos de Salvador e Santos (2011), da assinatura do Tratado do Mercosul e da Lei n. ${ }^{\circ} 11.161$ de 2005 . No que diz respeito do gênero discursivo, o referencial pautou-se nos estudos de Bakhtin $(2000,2003)$ e Bakhtin/Voloshínov (2006), Rodrigues (2005), Marcuschi (2005, 2007), Machado (2008) e Castro et al. (2009). Seguido de uma abordagem bakhtiniana referente ao tema, ao estilo e à construção composicional, uma vez que estes elementos foram retomados na análise da charge. Concernente a esta, foram empregados os conceitos de Romualdo (2000), Padilla García (2010) e Lessa (2007). Posteriormente, abordou-se o estudo de Fuentes (2001), sobre os componentes históricos, sociais e culturais referente às touradas, dados que se buscou desde a formação da Península Ibérica, ao que se denominou de Touradas na Espanha até atualidade. Finaliza-se este estudo com uma análise, com vistas a uma prática de ensino e de aprendizagem, que se trabalhe com a discursividade enunciativa, apresentada na charge selecionada.

PALAVRAS-CHAVE: Língua espanhola. Prática de ensino e aprendizagem. Gênero discursivo charge. Componentes histórico-social e cultural.

ABSTRACT: The present study seeks, through the reading of a Martin Favelis cartoon, referring to bullfighting, present a pedagogical approach that involves, besides a discursive reading of it, historical, social, cultural and political contents related to the Spanish language. In order to achieve this, at first, it was made a brief discussion regarding of the Spanish language teaching trajectory in Brazil, based on studies of Salvador and Santos (2011), the Mercosur Agreement's signature and the Law $n .^{\circ} 11.161$ (2005). Regarding the discursive genre, the reference was based on the studies of Bakhtin (2000, 2003) and Bakhtin/Voloshinov (2006), Rodrigues (2005), Marcuschi (2005, 2007), Machado (2008) and Castro et al. (2009). This text is followed by a Bakhtinian approach on the theme, style and compositional construction, once these elements were incorporated in the analysis of charge. Concerning this, it was used Romualdo (2000), Padilla García (2010) and Lessa (2007)

\footnotetext{
${ }^{1}$ Este artigo é uma adaptação do texto publicado nos Anais da JELL de 2013.

${ }^{2}$ Doutoranda do Programa de Pós-Graduação em Letras, da UNIOESTE e bolsista da CAPES.

${ }^{3}$ Professora Doutora do Programa de Pós-Graduação em Letras, da UNIOESTE.
} 
concepts. Later, it was approached the study of Fuentes (2001), about the historical, social, and cultural components related to the bullfighting, data that was sought from the formation of the Iberian Peninsula, and that was called Bullfighting in Spain until today. This study finishes up with an analysis, with a teaching and learning practice view, in which works with an enunciative discursivity presented in the selected cartoon.

KEYWORDS: Spanish language. Teaching and learning practice. Cartoon discursive genre. Historical-social and cultural components.

\section{INTRODUÇÃO}

No contexto do processo de ensino e de aprendizagem de uma dada língua no Brasil, pode-se considerar que é imprescindível que haja primeiro a conscientização de que o país não é monolíngue, e que há necessidade da inserção das línguas que são faladas nesta região do oeste paranaense, como, por exemplo, o alemão que vem a ser uma língua de imigrantes, como também, o espanhol, por ser uma língua de fronteira geográfica nesta região e, que no contexto institucional, isso seja relevante tanto para os educadores como para os aprendizes, uma vez que a importância que se deve dar ao ensino e a aprendizagem do espanhol, de acordo com o contexto sócio-histórico relacionado ao momento cultural, é o de preparar o aluno para ler criticamente as diferentes formas e linguagens de uma educação de línguas. Diante disso, pretende-se inferir competências possíveis de serem desenvolvidas por um aprendiz para que possa reconstruir as bases de crenças e mentalidades profundamente sedimentadas em todos os segmentos em que se ensina e se aprende línguas.

Assim, acredita-se que com base teórica concernente ao gênero discursivo é possível desenvolver um estudo de ensino e aprendizagem de acordo com a perspectiva bakhtiniana, que considera o dialogismo em relações interativas comunicativas como processos de produção de linguagem. Para tanto, primeiramente, realiza-se uma explanação referente ao gênero discursivo e sua finalidade, procurando compreender a relação existente entre a palavra, o ser humano e a vida em sociedade, em uma visão de sujeito discursivo que se utiliza da palavra, seja escrita, oral ou visual, para se manifestar discursivamente frente a outros sujeitos. Em seguida, apresenta-se de maneira sintetizada, os conceitos de tema, estilo e construção composicional, sob a ótica bakhtiniana, posto que estes elementos serão enfocados na análise.

Como o texto elencado para o estudo corresponde ao gênero discursivo charge, apresenta-se uma revisão de literatura que aborda questões relativas a esse gênero em específico, tendo como base, principalmente, as colocações de Romualdo (2000), quando trata sobre a construção composicional da charge, como também, a importância do traçado histórico apresentado. O autor em destaque faz uma explanação que vai desde a impressão da primeira imagem em jornais ao que hoje se conhece como charge.

A charge selecionada faz parte de uma coletânea de textos que compõem um livro didático para o ensino da Língua Espanhola, e corresponde a uma charge antiga. Diz respeito a uma das produções do chargista argentino Martin Favelis. Ressalta-se que mesmo realizando investigação bibliográfica e on-line, não foi possível recuperar a data de produção da charge em questão.

Considerando que este gênero entrelaça dois discursos, compreende-se que, para entendê-lo 
de maneira completa, é preciso retomar as condições de produção do texto. Contudo, o que se evidencia no presente momento é a utilização da charge selecionada como um meio alternativo, além do tradicional, de ensinar tópicos de cultura, política e história em conjunto com uma leitura possível do texto, com o intuito de gerar reflexões e criticidade por meio da compreensão da cultura do outro, ou seja, quando se trabalha ou se retoma uma charge antiga é necessário desenvolver uma investigação com vistas à recuperação da memória discursiva, bem como da temática abordada na mesma, uma vez que a finalidade deste gênero discursivo consiste em gerar reflexão e, consequentemente, riso, uma vez que o humor é marca essencial da charge.

Neste sentido, após a disposição da charge de Martin Favelis, realiza-se uma explanação histórica e cultural referente às Touradas, discorrendo sobre suas origens e práticas culturais, haja vista que para entender a crítica e o humor que a transpõe é preciso saber e conhecer ao que a mesma está se referindo, visto que seu objetivo não consiste apenas na ação de gerar o riso, mas também em levar o leitor a uma reflexão e argumentação lógica, pois a charge, assim como outro texto, objetiva convencer o leitor. Contudo, a este não é suficiente apenas ser convencido, precisa formar uma opinião.

Concernente ao conteúdo da charge, observou-se que, mesmo sendo antiga, é possível recuperar a intenção discursiva proposta, seja por meio da memória cultural ou histórica. Diante disso, por meio desse gênero discursivo, o professor de Língua Espanhola pode se valer de outros textos, como crônicas, notícias, poemas, entre outros, para que se possa abordar a temática das touradas, para poder desenvolver um diálogo entre seus alunos, pois é mais fácil falar do que se tem conhecimento. Sendo assim, ao trabalhar com diferentes gêneros discursivos, o professor acaba levando à sala de aula diferentes formas de abordar o mesmo assunto, ou seja, diferentes maneiras de dizer.

Para que esta situação se efetive de maneira satisfatória, ao professor cabe buscar por informações que sustentem a sua análise e argumentação, evitando uma reflexão inadequada e a imposição do seu ponto de vista aos alunos, visto que além de tornar a aula mais reflexiva e dialogal, pode criar, por meio da participação dos alunos, um momento de interação, reflexão e criticidade, quando diferentes posições e opiniões são apresentadas e formadas. Como também, possibilita que se compare a cultura nacional dos alunos com a cultura da língua estrangeira, possibilitando a esses aprendizes que percebam que ambas as línguas têm práticas em comuns e semelhantes, contribuindo para que o diferente não se constitua em um abismo que os separe, mas sim em uma ponte que os liga, ou seja, conhecer, por exemplo, "la realidad española es vital para que un extranjero se sienta, precisamente, menos extranjero, y tenga los recursos necesarios para relacionarse con los demás" (CATALÁ CARRASCO, 2007, p. 01) ${ }^{4}$.

Para tanto, com base nesse universo é que se propõe uma leitura da charge de Martin Favelis, levando-se em consideração os dados históricos, sociais e culturais, no entendimento dos elementos visuais verbais, não verbais e extraverbais. Para poder compreender a crítica exposta na imagem, a análise leva em consideração o humor e a sátira presentes no texto, bem como pontos de vista e divergências de opinião no que diz respeito à tradição e aos maus

\footnotetext{
${ }^{4}$ Tradução nossa: "a realidade espanhola é vital para que um estrangeiro se sinta, precisamente, menos estrangeiro, e tenha os recursos necessários para se relacionar com os demais" (CATALLÁ CARRASCO, 2007, p. 01).
} 
tratos de animais. É nos indícios da tradição histórico-cultural que se desenvolve a presente análise, uma visão de mundo específica, reflexiva, marcada pelo riso, pela subversão de valores oficiais, pelo caráter renovador e contestador do momento.

\section{A CONTEXTUALIZAÇÃO DO ENSINO DA LÍNGUA ESPANHOLA NO BRASIL}

As dificuldades de aceitação da Língua Espanhola como disciplina efetiva do currículo escolar teve início já na época do descobrimento e a pesar de ter sido e ainda ser a língua oficial dos seus vizinhos de fronteiras geográficas, observa-se que a sua difusão no Brasil não foi das melhores, tendo em vista às diferentes tentativas de aprovação pelas quais passou em mais de quinhentos anos.

Conforme dados históricos, logo após o descobrimento, foram os jesuítas quem ensinaram a Língua Portuguesa aos indígenas. Como esses naquela época faziam uso de uma língua geral, que era utilizada para a comunicação durante a extração da madeira, a Língua Portuguesa era ensinada como uma Língua Estrangeira, o que lhe concerne o título de primeira língua estrangeira ensinada no país, Salvador e Santos (2011). Contudo, em 1757 os jesuítas foram expulsos e no ano seguinte o Marquês de Pombal proibiu o uso e o ensino da língua geral, determinando o português como língua oficial e única do país, como pode ser constatado nos estudos de Heye e Vandresen (2006), Spinassé (2011), Altenhofen (2003) e Salvador e Santos (2011). Diante de tal postura governamental, diversas línguas indígenas existentes foram negadas e acabaram sendo extintas.

Depois da chegada da família real foram criadas as disciplinas de francês e inglês com o intuito de melhorar o ensino e desenvolver necessidades comerciais. Em 1837, com a fundação do Colégio Dom Pedro II, as duas disciplinas acima e outras duas mais (italiano e alemão) foram agregadas ao currículo escolar. Com a Reforma Capanema, em 1942, a língua alemã passa a deixar de fazer parte do currículo escolar e dá lugar ao Espanhol que passa a compor este. Enquanto o francês e o inglês possuíam uma carga horária de três anos, o espanhol tinha apenas um. Apesar de o espanhol ser considerado como uma língua modelo de patriotismo e valorização da cultura, a Língua Inglesa continuava a ser a privilegiada, por ser considerada a língua das transações comerciais e globalização mundial, Salvador e Santos (2011).

Em 1961, com a primeira Lei de Diretrizes e Bases da Educação Nacional (LDB), as Línguas Estrangeiras passaram a ter caráter complementar e, em 1976, estas passaram a ser obrigatórias para o Ensino Médio e um acréscimo ao Ensino Fundamental. E mais uma vez verificou-se o predomínio da Língua Inglesa. Novamente, em 1980, estudiosos passam a discutir a importância do ensino da Língua Espanhola nas escolas, mas vista sob o estereótipo de língua fácil, por ser semelhante ao português, acaba sendo desprestigiada.

A partir de 1989, com a assinatura do Tratado do Mercosul (Mercado Comum da América do Sul), estabelecido em 1991, pelo tratado de Assunção, a Língua Espanhola adquiriu valor econômico e passou a ser prestigiada no meio escolar. Com a LDB de 1996, fica declarada a obrigatoriedade do ensino de uma Língua Estrangeira Moderna (LEM) no Ensino 
Fundamental a ser escolhida pela escola, enquanto que o Ensino Médio deve ter uma língua obrigatória e outra optativa, porém, novamente, verifica-se o predomínio da Língua Inglesa.

Mas é com a Lei 11.161, de 2005, que o espanhol passa a ser valorizado, uma vez que esta lei estabelece a oferta obrigatória desta língua no Ensino Médio, tendo as instituições escolares até 2010, para porem a mesma em prática. Já, para o Ensino Fundamental, a inserção da Língua Espanhola foi facultativa.

Constata-se assim, a crescente importância que o ensino da língua espanhola tem conquistado no Brasil, tanto no país como nas regiões de fronteiras geográficas de hispano-falantes. Condição que se desenvolveu, inicialmente, com a criação do Mercosul, que hoje, em virtude de mudanças, inclusão de outros países, conflitos e competitividade, só existem duas línguas principais: o português e o espanhol, que detém uma importância global, isso pelo número de falantes da língua nesse mundo globalizado de intercâmbios comerciais. Ou, ainda, nesse mundo global, contraditório de relacionamentos e de identidades regionais fragmentadas, a linguagem tem um papel fundamental: a intersecção de uma linguagem internacional e globalizada se faz evidente por facilitar a comunicação verbal (oral, escrita ou visual) por meio de uma língua franca, respeitando fatores sócio-históricos, culturais e linguísticos.

Como observado, o espanhol, já há algum tempo, tem se consagrado uma língua internacional, tanto na Europa como na América, como língua de intercâmbio comercial internacional, na diplomacia, nos meios científicos, na publicidade, em negociações e nas interações comunicativas entre os povos. Por isso, a língua espanhola não pode ser vista somente como um fenômeno lingüístico, mas sim como uma língua franca, tanto no mundo globalizado como nas regiões de fronteiras com o Brasil.

Diante disso, entende-se que existe uma interação comunicativa verbal, visual e/ou escrita entre os falantes dos dois idiomas (português e espanhol), tanto de um lado da fronteira como do outro, possibilitando para que se evidenciem formas efetivas de comunicação entre as pessoas, respeitando as idiossincrasias linguísticas, históricas, sociais e culturais. Contudo, o educador deve estar consciente e ensinar aos aprendizes a utilizar a língua, promovendo a solidariedade, o respeito e a cidadania em regiões de fronteiras geográficas e entre os povos, quando do uso do espanhol calcado em práticas de aprendizagem de forma emancipatória e transformadora, que ponham abaixo a crescente desvalorização que tem surgido no campo do ensino do espanhol que, sem receber o devido respeito à variabilidade linguística, histórica e cultural, têm sido vítima de uma série de mitos, como o estereótipo de língua fácil.

O que se espera é que o ensino do espanhol atenda às exigências dos novos tempos, fomentando práticas pedagógicas que levem o educando dialogar com gêneros discursivos, a história, a cultura e a sociedade a que pertencem os seus falantes nativos, uma vez que, segundo Leffa (2006) e Rajagopalan (2010), e pensando no espanhol como língua franca, o que se tem hoje é uma língua sem dono, sem tutela e custódia, de nenhuma nação particular, pertencendo sim a quem dela faz uso ${ }^{5}$.

\section{O GÊNERO DISCURSIVO COMO INSTRUMENTO PARA O ENSINO DO}

\footnotetext{
${ }^{5}$ Os dois autores pesquisam a respeito da língua inglesa e fazem a colocação que se seguiu no texto fazendo referência ao inglês, ocorre, contudo, que a mesma situação pode ser estendida à língua espanhola, haja vista a quantidade de falantes existentes no mundo e que extrapolam fronteiras geográficas.
} 


\section{ESPANHOL}

\subsection{O Gênero Discursivo}

Em uma perspectiva bakhtiniana, os gêneros do discurso são formas de enunciados construídos socialmente e cristalizados em práticas comunicativas diversas. Diante disso, compreende-se que os gêneros discursivos são apreendidos por meio da interatividade em situações comunicativas cotidianas e correspondem àquilo que se crê que sejam.

Sendo os gêneros discursivos produzidos nas esferas da comunicação verbal (oral, escrita ou visual) (Bakhitn 2003 e Bakhtin/Voloshinov 2006), pode-se dizer que desde a origem humana o homem vem se comunicando, seja por desenhos pintados nas cavernas, gestos, murmúrios, grunhidos, gritos, gemidos ou palavras, tendo em vista que "cada época e cada grupo social têm seu repertório de formas de discurso na comunicação sócio-ideológica" (BAKHTIN/VOLOSHINOV, 2006, p. 44). O que possibilita que se afirme que, cotidianamente, os sujeitos estão vinculados à linguagem, tanto visual quanto verbal.

Os gêneros discursivos correspondem aos veículos de comunicação dos sujeitos que vivem em sociedade. São os condutores e mediadores do ato comunicativo, possibilitando que as pessoas se entendam e progridam discursivamente em sociedade. Como formas comunicativas são adquiridas por meio de processos interativos, isto é, pela interação verbal, haja vista que são construídos socialmente e efetivados em práticas comunicativas cotidianas e variadas. Portanto, destaca-se que "gêneros e discurso passam a ser focalizados como esferas de uso da linguagem verbal ou da comunicação fundada na palavra” (MACHADO, 2008, p. 152).

Esclarece que os "gêneros são línguas em uso, são línguas vivas, são instrumentos de comunicação/interação. São instrumentos indispensáveis, todas as pessoas usam gêneros para se comunicar, para interagir" (CASTRO et al., 2009, p. 651). São edificados socialmente e concretizados em práticas comunicativas cotidianas variadas porque "todos os diversos campos da atividade humana estão ligados ao uso da linguagem" (BAKHTIN, 2003, p. 261). Os gêneros também, "contribuem para ordenar e estabilizar as atividades comunicativas do dia-a-dia" (MARCUSCHI, 2007, p. 19), visto que "passam a ser focalizados como esferas de uso da linguagem verbal ou da comunicação fundada na palavra" (MACHADO, 2008, p. 152).

Bakhtin explica que "cada enunciado particular é individual, mas cada campo de utilização da língua elabora seus tipos relativamente estáveis de enunciados, os quais denominamos gêneros do discurso" (BAKHTIN, 2003, p. 262 - grifos do próprio autor). Assim, evidenciase que o gênero é a realidade da língua e que está se efetiva por meio de enunciados que só se revelam em uma dada situação e na cadeia dos textos, pois está ligado às relações dialógicas peculiares.

Neste sentido, pode-se dizer que os gêneros discursivos consistem no instrumental que possibilita a comunicação humana no cotidiano e, que se constroem por meio de atividades comunicativas programadas e/ou imediatas, podendo ocorrer de maneira visual, oral ou escrita, no entanto, sempre devem se adaptar ao contexto em que são ou serão utilizados. 
Os gêneros, assim como surgem, também podem desaparecer, e isso ocorre em virtude do uso que se fazem deles, como, por exemplo, a carta e o e-mail, em que este tem substituído consideravelmente o uso da outra em eventuais situações comunicativas. O desaparecimento do gênero também "se dá pela ausência das condições sociocomunicativas que o engendram" (RODRIGUES, 2005, p. 166), isto é, com o acesso às novas tecnologias e o acesso à internet, ficou mais fácil, prático e rápido enviar um e-mail, ao invés de escrever uma carta e encaminhá-la via correio.

Ocorre que nem sempre um gênero desaparece por conta da diminuição de seu uso discursivo, em alguns casos verifica-se que houve uma adaptação ou modificação naquele gênero em virtude da necessidade de se atender a outras situações comunicativas. Para tanto "quanto mais um gênero circula, mais ele é suscetível de mudanças e alterações por se achar estreitamente ligado a uma moldagem social” (MARCUSCHI, 2005, p. 25).

Para Bakhtin (2003) e Bakhtin/Voloshinov (2006) existe um elo entre a vida e a língua, entre o sujeito e o enunciado, pois é a partir dessa relação do sujeito com a língua e com o meio, que novos gêneros acabam por surgir. Como o "homem tem inerentemente uma necessidade individual de se expressar e uma necessidade social de se comunicar" (KATO, 1987, p. 12), a forma na qual se comunica pode e diz muito sobre si mesmo e põe em evidência suas intenções discursivas, pois a partir da situação, do meio social e por meio da palavra se constitui como sujeito discursivo.

Comunicar consiste em uma prática cotidiana e fundamental ao ser humano, tendo em vista que é por meio da linguagem que se transmite histórias e ideais, ou como diz o mestre, são os gêneros do discurso as "correias de transmissão que levam da história da sociedade à história da língua" (BAKHTIN, 2000, p. 285), fazendo com que a vida registre a história e que esta penetre nos enunciados, transmitindo aos constituintes dos discursos, informações, opiniões ou pontos de vista. Tudo consiste em um processo de interação entre a língua, o sujeito, a cultura e a história, uma vez que é a vida do sujeito e a sua relação com o meio a que pertence quem possibilita o surgimento de enunciados e de novos gêneros.

A seguir discute-se, brevemente, sobre os conceitos de tema, estilo e construção composicional sob as bases da perspectiva bakhtiniana, uma vez que, assim como, o gênero discursivo e o enunciado são fundamentais no trabalho com o texto, a abordagem desses três elementos também o são, na medida em que contribuem na análise, leitura e interpretação textual.

\subsection{A Situação Enunciativa sobre Tema, Estilo e Construção Composicional da Linguagem}

Sendo os gêneros do discurso enunciados, há que considerar que refletem "as condições específicas e as finalidades de cada referido campo, não só por seu conteúdo (temático) e pelo estilo da linguagem [...] mas, acima de tudo, por sua construção composicional" (BAKHTIN, 2003, p. 261). Diante disso, sob a perspectiva bakhtiniana, discorre-se a respeito desses três elementos presentes na leitura da charge selecionada.

Nas considerações de Bakhtin/Voloshínov, tema ou conteúdo temático corresponde ao "sentido da enunciação completa" (BAKHTIN/VOLOSHÍNOV, 2006, p. 133). Entende-se, 
então, que o tema dever ser algo único, não reiterável e individual, assim como o é a própria enunciação. Os autores ainda destacam que "o tema da enunciação é determinado não só pelas formas linguísticas que entram na composição [...], mas igualmente pelos elementos não verbais da situação" (BAKHTIN/ VOLOSHÍNOV, 2006, p.133).

Os pensadores enfatizam que o tema "da enunciação é concreto, tão concreto como o instante histórico ao qual pertence. Somente a enunciação tomada em toda a sua amplitude concreta, como fenômeno histórico, possui um tema" (BAKHTIN/ VOLOSHÍNOV, 2006, p. 134). Assim sendo, para que se compreenda o tema e o mesmo passe a lhe fazer sentido, é fundamental que o contexto seja recuperado, tendo em vista que o tema para Bakhtin/Voloshínov "é um sistema de signos dinâmico e complexo, que procura adaptar-se adequadamente às condições de um dado momento da evolução" (BAKHTIN/ VOLOSHÍNOV, 2006, p. 134 - grifos dos próprios autores). Os estudiosos ainda declaram que no interior do tema existe a significação, e que não há como um existir sem o outro. Por significação entende-se "os elementos da enunciação que são reiteráveis e idênticos cada vez que são repetidos” (BAKHTIN/ VOLOSHÍNOV, 2006, p. 134 - grifos dos próprios autores).

A temática, em síntese, corresponde ao sentido do enunciado. O tema é o assunto na situação, é o conteúdo, em que se integram visões de mundo, e somente por meio da compreensão ativa e que pode ser apreendido, ou seja, não há como apreender o tema sem reconhecê-lo no enunciado, sem interagir e reconhecer-se no mesmo.

Quanto ao estilo, este se revela pela linguagem e "integra a unidade de gênero do enunciado como seu elemento" (BAKHTIN, 2003, p. 266). Quase todos os gêneros permitem, a partir de sua construção composicional, o estilo individual de quem fala ou escreve. Às vezes o próprio gênero, por conter uma estrutura mais padronizada, barra o estilo individual, Bakhtin (2003), mas, podem surgir alterações estilísticas, pois, as "mudanças históricas dos estilos de linguagem estão indissoluvelmente ligadas às mudanças dos gêneros do discurso" (BAKHTIN, 2003, p. 267).

A cerca da seleção do gênero a ser empregado nos discursos, verifica-se que a "situação e os participantes mais imediatos determinam a forma e o estilo ocasionais da enunciação. Os estratos mais profundos da sua estrutura são determinados pelas pressões sociais mais substanciais e duráveis a que está submetido o locutor" (BAKHTIN/ VOLOSHÍNOV, 2006, p. 118), ou seja, "o estilo é pelo menos duas pessoas ou, mais precisamente, uma pessoa mais seu grupo social na forma do seu representante autorizado, o ouvinte - o participante constante na fala interior e exterior de uma pessoa" (BAKHTIN/ VOLOSHÍNOV, 1976 [1926], p. 16).

Observa-se que mesmo o estilo sendo próprio do gênero ou do autor ele não é individual, pois está impregnado de referenciais e situações vividas cotidianamente em um coletivo, em sociedade, tendo em vista que para que haja a compreensão de determinado fato é preciso que este seja reconhecido pelos demais interlocutores. Pode-se dizer que o estilo é uma construção coletiva, assim como, o são as palavras que não são ocas, em que cada um as preenche com o conceito ou significado que lhe convém, mas construções dialógicas cheias de sentido iguais e diferentes, sentidos que são resgatados por cada sujeito de maneira individual e coletiva, e que apenas se concretiza no contexto. 
E, apesar de cada autor poder apresentar um estilo próprio, sua linguagem sempre estará impregnada de julgamentos de valor criados em sociedade, visto que "o estilo, longe de se esgotar na autenticidade de um indivíduo, inscreve-se na língua e nos seus usos historicamente situados" (BRAIT, 2013, p. 81), pois, assim como, "não existem palavras sem voz, palavras de ninguém” (BAKHTIN, 2003, p. 330), também não existe um estilo puro e alheio às situações e pressões sociais a que pertence o locutor.

Sendo assim, pode-se dizer que o estilo pode corresponder tanto ao sujeito autor, como à estrutura do gênero, isto é, a escolha de uma palavra, de uma expressão, da pontuação, o uso de ironia, humor, tristeza, alegria, entre outros, determinados usos linguísticos, gramaticais ou lexicais, correspondem a marcas estilísticas do autor do discurso, enquanto que a padronização e a formatação do gênero correspondem ao estilo deste gênero, como, por exemplo, uma bula de remédio que, devido a sua construção composicional, inviabiliza o escritor de expor as informações científicas em versos ou valendo-se de figuras de linguagem. Assim, pode-se dizer que o estilo está tanto para o gênero quanto para o autor.

A construção composicional, por sua vez, está próxima ao estilo do gênero. É a responsável pela organização estrutural do texto, é quem estabelece e diferencia um gênero discursivo de outro e determina os tipos de construção de conjuntos. Faz referência aos parágrafos, títulos, capítulos, imagem, som, movimento, cores, cheiros, textura, foco, iluminação; e do discurso direto, indireto, entre tantos outros, que, de certa forma, representam determinado gênero, tornando-o reconhecível, como, por exemplo, o poema, que pode apresentar diferentes estruturas composicionais, como um soneto, um haicai, imagético (estar disposto de maneira que forma uma imagem) ou até mesmo em prosa, e nem por isso deixará de ser um poema, contudo, não há como confundir este gênero com o gênero piada ou bula de remédio.

Diante do exposto, verifica-se que o tema, o estilo e a construção composicional são elementos fundamentais do gênero discursivo, e como tais determinam as escolhas estilísticas e enunciativas de seus autores que devem sempre levar em consideração o meio discursivo ao qual pertencem.

\section{O GÊNERO DISCURSIVO CHARGE}

De acordo com os estudos de Romualdo (2000), a charge passou a ser considerada como um texto apenas no século XIX, mas para que isso ocorresse foi preciso que os jornais, primeiramente, trouxessem em suas páginas a ilustração. Condição posta em prática em 1835, nos Estados Unidos, com a publicação de uma gravura com o intuito de ilustrar uma reportagem. No entanto, ainda nesta época, a apreensão da imagem em destaque no jornal era de certa forma, praticamente incompreensível, uma vez que as máquinas destinadas à impressão não eram próprias para esse fim. Mesmo assim, o público acabou se interessando pelas ilustrações que concomitantemente foram ganhando espaço ao lado das notícias.

Ainda valendo-se das palavras de Romualdo (2000), as caricaturas, componentes da charge, surgiram um pouco antes da Revolução de Independência dos Estados Unidos, em 1976, mas acabaram obtendo um valor de criticidade, somente em 1985. Já no Brasil, apesar de alguns pesquisadores afirmarem que a caricatura abrolhou, em 1831, o primeiro registro que se tem de uma caricatura publicada, mesmo que comercializada individualmente, data de 1942 e faz referência a uma "sátira contra Justiniano José da Rocha, de 14 de dezembro de 1837" 
(ROMUALDO, 2000, p. 13).

Mas, afinal, o que vem a ser a charge? A charge corresponde a um gênero discursivo, assim como, um conto, uma crônica ou um e-mail. E como qualquer outro gênero, apresenta características que lhe são próprias, ou seja, essas que são responsáveis por estabelecer determinado gênero como sendo um conto, e não uma crônica, por exemplo.

Neste sentido, pode-se dizer que cada gênero discursivo apresenta suas próprias especificidades que as distingue de outros. No caso da charge, um elemento tem presença marcante e consiste no imprescindível para defini-la: a imagem que, por conseguinte, deve estar atrelada a outras características fundamentais, como o contexto de publicação e de circulação, a criticidade, o humor, a atualidade e a relação com algum acontecimento, fato ou pessoa política. Quanto ao meio de publicação, por estar, frequentemente, atrelada aos acontecimentos atuais e, principalmente, políticos, têm presença marcante e cotidiana nos jornais. No entanto, a charge também pode constar em revistas e livros, estes geralmente de cunho didático.

A charge por estar vinculada a produção e a criação humana, se caracteriza como um produto sociocultural que, ao arquitetar-se por meio de um desenho ou caricatura, o que a fundamenta, pode apresentar ou não a linguagem verbal, haja vista que não há uma obrigatoriedade da presença do verbal neste gênero discursivo, uma vez que um desenho bem elaborado e caracterizado possibilita que o leitor bem informado apreenda a mensagem abalizada apenas pela imagem.

Portanto, a charge é "um tipo de texto que atrai o leitor, pois enquanto imagem, é de rápida leitura, transmitindo múltiplas informações de forma condensada" (ROMUALDO, 2000, p. 5). Respalda-se, também, na colocação de Padilla García, que esclarece que no momento da leitura do texto chargico "el dibujo o el texto pueden ser el elemento principal a la hora de interpretar el contenido y el mensaje de la viñeta" (PADILLA GARCÍA, 2010, p. 6) ${ }^{6}$.

Ainda no que diz respeito à definição do gênero, Romualdo (2000), esclarece que a representatividade da charge pode ocorrer por meio de um quadro ou mais, assim como, as histórias em quadrinhos, porém, tem um número de quadros reduzido. Em situações que apresenta mais de um quadrinho, indica que a temática abordada segue uma sequência de ações, posto que, têm a intencionalidade de mostrar ao leitor um panorama: o antes e o depois, o hoje e o passado ou o hoje e o futuro. No caso de múltiplos quadros, a ordem estabelece que a leitura se desenvolva da esquerda para a direita e de cima para baixo.

A charge, assim como outros gêneros discursivos, possui um propósito. Na charge o mesmo consiste em fazer uma crítica ou uma análise, sempre fundamentada pelo humor, e pela sátira. O riso somente pode efetuar-se se a charge estiver bem construída, coerente e coesa, ou seja, apresentar uma relação harmoniosa entre os elementos pictóricos e gráficos que a compõem, para que transmita sentido e possibilite a reflexão e, consequentemente, permita que o riso se efetue na pessoa do leitor.

\footnotetext{
${ }^{6}$ Tradução nossa: "o desenho ou o texto podem ser o elemento principal no momento de interpretar o conteúdo e a mensagem da charge” (PADILLA GARCÍA, 2010, p. 6).
} 
Já que a charge visa criticar por meio do humor, Padilla García esclarece que o mesmo "potencia las relaciones afectivas entre los estudiantes, dessarolla la memória visual y auditiva, facilita la adquisición del vocabulario y favorece en general la práctica oral de la lengua" (PADILLA GARCÍA 2010, p. 4) ${ }^{7}$. Mesmo que a autora faça referência ao contexto de sala de aula, a charge aciona e desenvolve diferentes funções nos mais diferentes leitores, que a seu modo vão refletir de uma maneira mais simples ou mais complexa, a depender do grau de familiaridade que estabelece com o assunto abordado.

Nesse sentido, torna-se condição imprescindível para compreender e refletir sobre o conteúdo de uma charge conhecer o fato, o personagem ou o assunto que a mesma está se referindo, do contrário, a inferência e a interpretação pode não ocorrer, e, nem mesmo, o riso marca a sua presença, pois se torna dificílimo rir de algo que se desconhece. Para tanto, "o público leitor deve ter informações suficientes para efetuar o destroncamento semântico determinado entre as palavras e imagens para poder obter uma compreensão ativa desse gênero" (LESSA, 2007, p. 12).

Como as charges fazem referência a contextos recentes, sua leitura depende muito do resgate do contexto discursivo nelas apresentada. Por serem textos curtos e de fácil leitura, chamam a atenção do leitor e, consequentemente, por circularem, geralmente, em jornais, sua produção é farta e inovadora. Essa inovação constante se justifica em decorrência "das transformações constantes que vivem os homens e as sociedades" (ROMUALDO, 2000, p. 42), o que contribui para dificultar a leitura de charges fora de sua época, haja vista que essas modificações fazem com que o contexto social se altere e, "por isso, quando revemos velhas caricaturas ou charges não compreendemos muitas vezes a intenção e o humor desses textos" (ROMUALDO, 2000, p. 42).

Entretanto, o que fazer quando se encontra uma charge fora de sua época? Quando não há como relacioná-la com os contextos discursivos atuais?

Ler ou trabalhar com uma charge descontextualizada ou antiga é possível. Talvez consista em uma atividade mais trabalhosa, mas não vem a ser impossível. O necessário, nesses casos, é pesquisar sobre a mesma, sobre o assunto em questão, a quem se destina e o que ou quem está criticando. Em alguns casos, a temática da charge aborda contextos culturais que podem ser relacionados à história e à cultura de um povo ao qual o conteúdo faz referência, como é o caso da charge que compõe as figuras da presente reflexão. Neste caso, é possível fazer um resgate histórico-cultural e conhecer mais sobre outros povos, como afirma Padilla García, ao tratar do humor presente nas charges, cita que este: "[...] también nos ofrece información muy útil sobre las costumbres y características culturales de un país [...]” (PADILLA GARCÍA, 2010 , p. 4) ${ }^{8}$.

Dessa forma, constata-se que a charge pode auxiliar o professor de Língua Espanhola no contexto de sala de aula, contribuindo não só para gerar aulas de leitura, mas sim leituras reflexivas e criativas, para que os alunos possam entender e reconhecer a cultura e a história

\footnotetext{
${ }^{7}$ Tradução nossa: "fortalece as relações afetivas entre os estudantes, desenvolve a memória visual e auditiva, facilita a aquisição do vocabulário e favorece em geral a prática oral da língua" (PADILLA GARCÍA, 2010, p. 4).

${ }^{8}$ Tradução nossa: “[...] também nos oferece informação muito útil sobre os costumes e características culturais de um país [...]” (PADILLA GARCÍA, 2010, p. 4).
} 
do outro, podendo verificar os componentes diferentes e semelhantes da sua.

Diante de tão rica diversidade de gêneros, faz-se uma análise para uma prática de ensino e aprendizagem sobre o gênero discursivo charge que, como qualquer outro gênero, tem suas características próprias.

\section{A CHARgE COMO PRÁTICA DE ANÁliSE PARA UMA APRENDIZAGEM DE ENSINO DE ESPANHOL}

Para este momento delimitou-se uma charge de Martin Favelis disponível no livro didático Síntesis: curso de lengua española de Iván Martin (2010), que conforme a fonte citada, também pode ser encontrada no site $<$ http://2.bp.blogspot.com $>$. Mesmo buscando no acervo do artista, não foi possível verificar quando a mesma foi publicada, mas em relação a sua temática, pode-se dizer que esta charge faz referência às touradas e às corridas de touros, ambas como práticas culturais históricas de origem espanhola. Contudo, para este texto, discute-se apenas a temática das touradas.

Como já mencionado, por ser uma charge antiga, pode ocorrer que sua leitura se torne mais complicada, mas não impossível, uma vez que tal fato não prejudica ou impossibilita o ato reflexivo e crítico estabelecido por este gênero discursivo. Neste caso, irá requerer do leitor ou docente que se pesquise sobre a temática abordada. Como a charge está compondo o material didático e o mesmo não determina um contexto específico para a mesma, nem traz textos de apoio no transcorrer do capítulo, há uma possibilidade de leitura que pode tratar sobre os aspectos culturais e históricos das touradas, e ir ao encontro de paradigmas que condenam a violência contra os animais, pois apesar de ser uma tradição cultural, também é vista como uma prática questionável, e é exatamente isto que a charge faz, critica uma situação questionável.

Figura 1 Charge de Martin Favelis

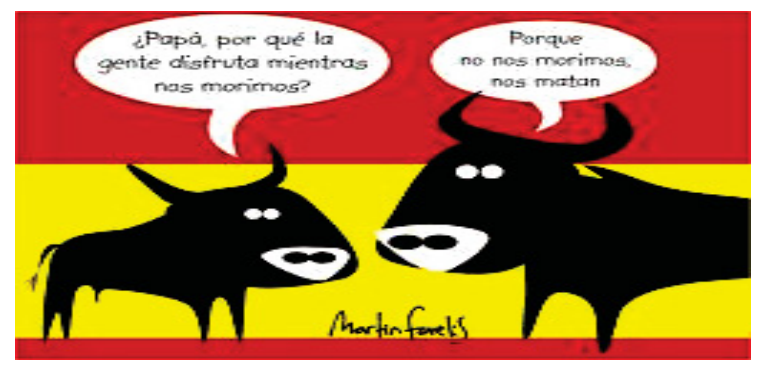

Fonte: http://2.bp.blogspot.com

\section{1 O Componente Cultural e Histórico}

Para esta prática de ensino e aprendizagem, inicia-se o estudo da língua espanhola, com a charge que faz referência à prática das touradas na Espanha, que tem se colocado através dos tempos como fonte inesgotável de leituras, e, é nesse universo, que se propõe uma leitura original e inovadora. 
Diante do fato de que todos os elementos imagéticos da charge contribuem para o seu entendimento, pode-se afirmar que a crítica está se dirigindo à tradição espanhola das touradas e das corridas de touros, haja vista que as cores, vermelho e amarelo, que compõem o fundo da imagem, fazem alusão à bandeira da Espanha, com três faixas horizontais, a de cima na cor vermelha, a do meio em amarelo e de baixo novamente vermelha. Compreende-se também que esta escolha não é aleatória, pois nenhum discurso é neutro. Acredita-se que a relação com a pátria Andaluza se constrói em decorrência de ter sido na Espanha que as Touradas surgiram e que ainda são praticadas. Assim como em outros países, existem regiões na própria Espanha que não desenvolvem esta prática, como também, se verifica que há outros países que a deixaram de praticar em virtude da lei de proteção aos animais e outros que ainda a praticam.

Mas, enfim o que são e no que consistem as touradas?

Em uma visão realista, pode-se dizer que as touradas são duelos levados até a morte, em que touro e toureiro se enfrentam em um jogo de agilidade e resistência, de vida ou morte, em que sai vitorioso o toureiro quando atinge ao touro com suas diversas armas - no decorrer do "espetáculo" o homem golpeia e esfaqueia o animal que, como em um paradoxo, foge e o enfrenta -, ou o touro quando atinge o toureiro com suas armas fatais, chifres e cabeça, levantando-o do chão e arremessando-o no ar.

Segundo Fuentes (2001), as touradas representam muito mais do que um mero duelo entre homem e animal, uma vez que as figuras do touro e do toureiro são muito representativas na cultura espanhola. O que para uns é considerado uma tradição, para outros é visto como uma barbarie. Essa divergência de opiniões consiste no alimento que sustenta a vida em sociedade e que ampara diferentes pontos de vista.

Para se compreender o nascimento da tradição espanhola, é preciso voltar à Pré-história e entender como se formou a Península Ibérica (Portugal, Espanha e parte da França). Os povos nômades que habitavam a região foram evoluindo com o passar dos anos e passaram de uma economia depredadora para uma produtora, isto é, com o desaparecimento do bisão entre os anos 8.000 e 5.000 a.C., os povos precisaram mudar a sua dieta e, com isso, iniciou-se um modo de vida abalizado no plantio.

A península que na antiguidade era povoada pelos celtas e ibéricos foi sofrendo invasões dos povos indo-europeus e do mediterrâneo, e, entre os séculos X e III a.C., foi colonizada pelos fenícios, gregos e cartagineses que fundaram na península colônias para o comércio. O povo celta teve influência indo-europeia, enquanto que os ibéricos a mediterrânea.

Em meados de 218 a.C., os romanos desembarcaram em Emporion e deram início a uma sucessão de guerras, com o intuito de dominar a península. Os três primeiros conflitos ficaram conhecidos como Guerras Púnicas e ocorreram contra os cartagineses. Os romanos conquistaram totalmente a península após a quarta fase ou guerra, 29 a 19 a.C., e com as derrotas dos povos restantes iniciaram o processo de romanização e denominaram a então Península Ibérica como Península Hispânica. Contudo, em decorrência das invasões dos povos bárbaros no século IV, o Império Romano entra em crise e decadência.

Os povos visigodos constroem um reinado que vai de 418 a 711. A península sofre a invasão 
muçulmana, e por 800 anos, fica sob o reinado Al-Andaluz. Em 1453, caí Constantinopla que era a capital do Império Bizantino e também marco de uma rota comercial entre a Europa e o Oriente. Situação que fez com que se buscasse por novas rotas comerciais, levando Portugal e Espanha ao encontro da África e da América.

O encontro entre os habitantes do que se denominou de Velho Mundo com os povos indígenas que habitavam o Novo Mundo, não foi nada pacífico, a colonização de exploração fez com que muitos índios morressem e as suas culturas desaparecessem, haja vista o trabalho forçado a que eram expostos. Como os colonizadores necessitavam de mão de obra, iniciou-se o tráfico de escravos.

Diante do exposto, compreende-se que a formação do que hoje se denominou de Espanha, foi possível graças às colonizações e contribuições de uma gama diversificada de povos e culturas. Do mesmo modo, observa-se que a relação do povo espanhol com os touros corresponde a uma história antiga e tem relação com o bisão que servia de alimentação aos povos nômades que habitavam a península. Fuentes (2001) declara que o mapa da Península Ibérica, como pode ser visualizado na imagem de número dois, "se assemelha a pele de um touro" (FUENTES, 2001, p. 17). É porque nação e animal são representativos para esse povo.

Figura 2 Imagem de satélite da Península Ibérica.

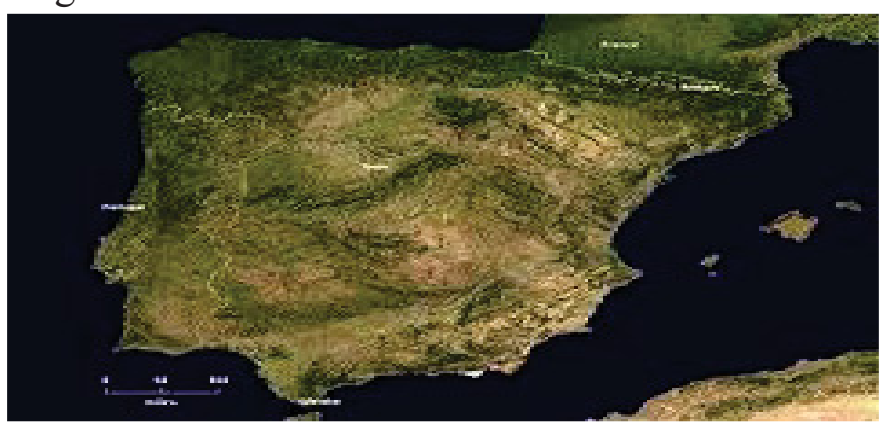

Fonte: www.google.com.br (imagens)

Figura 3 Imagem do Bisão nas grutas de Altamira

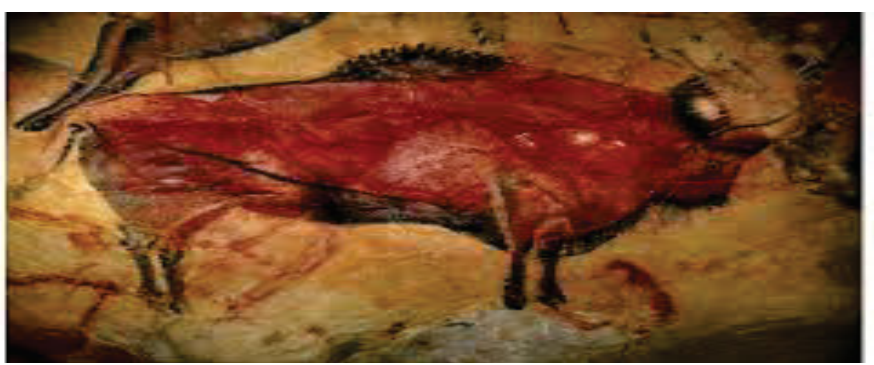

Fonte: www.google.com.br (imagens).

Já, na figura três, é possível observar o bisão, animal que era utilizado para a alimentação dos habitantes da península. O bisão consiste em um dos primeiros ícones da humanidade, e tem no touro espanhol a sua representatividade. Para os espanhóis, a figura do touro representa o poder e a vida, é imagem de fertilidade e força adquirida por meio dos cultos do mediterrâneo. 
Diante de tão representativa admiração e endeusamento, o touro passou a ser visto também "como um companheiro de jogos" (FUENTES, 2001, p. 19). Ao tratar da história da Espanha, o autor lança mão da mitologia grega para descrever a relação dos espanhóis com os touros e esclarece que:

[...] o primeiro matador é o herói ateniense Teseu, vencedor do Minotauro. Hércules, seu contemporâneo, é quem leva a mitologia do touro para a Espanha. Como Teseu, Hércules mata em Creta um touro com hálito de fogo. Mas também viaja para a Espanha, onde rouba o rebanho de touros vermelhos pertencentes ao gigante de três corpos, Gerião, e os leva de volta à Grécia. [...] Hércules demonstra sua nobreza ao devolver uma parte do gado à Espanha, em reconhecimento da hospitalidade que ali recebeu. A partir desse momento, o rei Crisaor estabeleceu na Espanha o rito anual de um touro sacrificado em honra de Hércules (FUENTES, 2001, p. 19).

Essa relação de veneração mostra como é visto o touro espanhol, sua representatividade e percurso que conduz a um só lugar da Espanha, a um lugar-comum que se compartilha e se encontra: a praça de touros (figura 4), onde o povo se reúne para ver o que era apenas um rito. Esse caminho percorrido para se chegar à praça de touros é representativo na medida em que simboliza o caminho trilhado pelos povos colonizadores de toda a Península Ibérica.

Figura 4 Imagem representativa de uma Praça de Touros

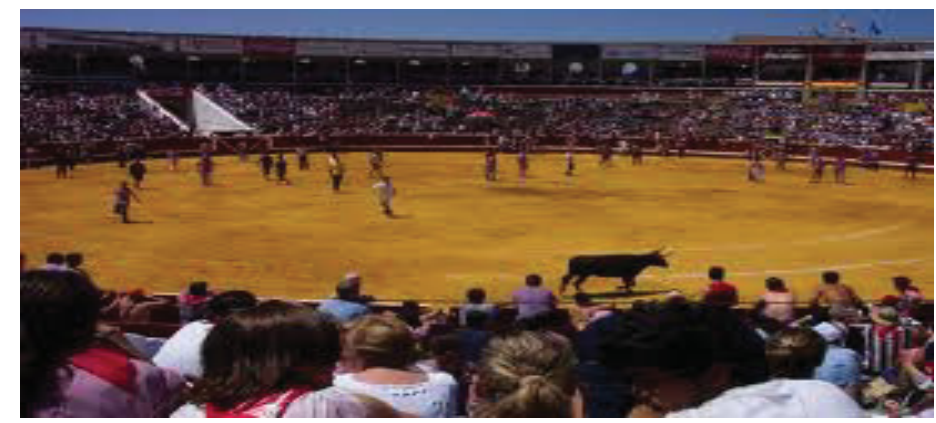

Fonte: www.google.com.br (imagens).

E é justamente na praça de touros que

[...] o povo encontra a si mesmo e encontra o símbolo da natureza, o touro, o que ocorre até o centro da praça, perigosamente assustado, fugindo para adiante, ameaçado mas ameaçador, cruzando a fronteira entre o sol e a sombra que divide a arena como a noite e o dia, como a vida e a morte. O touro sai correndo para se encontrar com o antagonista humano, o matador, em seu traje de luzes (FUENTES, 2001, p. 20).

O matador em suas vestimentas coloridas, postura ereta e com passos de balé se movimenta diante do touro. O toureiro representa o povo e tem sua coragem avaliada pela ousadia em aproximar-se o máximo possível do touro sem ser atingido por este, provocando-o com o pano vermelho que, por conta dos movimentos, deixa o animal enfurecido. Ao toureiro cabe entreter a plateia que grita "olé!" cada vez que o touro é enganado. A tourada termina quando o valente atinge o touro com todas as suas armas, e após o golpe final, quando o animal encontra-se caído e sangrando, o toureiro retira as duas orelhas do animal ferido. Estas são 
seus troféus. Mas assim como o velho ditado diz: "um dia da caça e outro do caçador", nem sempre sai vitorioso o toureiro, às vezes, cabe ao touro a vitória e àquele dor, ferimentos e até mesmo a morte.

Porém, mesmo sendo considerada uma tradição, as touradas já foram proibidas em inúmeros países, como Portugal e Brasil. Aqui no Brasil, as touradas eram uma prática comum no século passado, sendo proibida, junto com as rinhas de galo, em 1934, por Getúlio Vargas. Havia praças de touros nas cidades de Curitiba, São Paulo, Salvador, Cuiabá, Santos, Campinas, Porto Alegre e Rio de Janeiro. Em 1922, realizaram-se touradas para comemorar o centenário da Independência.

$\mathrm{Na}$ própria Espanha existem lugares em que as touradas estão proibidas, como as Ilhas Canárias que foram as primeiras a proibi-la em 1991, com a aprovação da Lei de Proteção de Animais. Em 2010, por meio de uma inicitiva popular que contou com 180.000 cidadãos, foi proibida qualquer prática de tourada. Porém, como está historicamente comprovado, as touradas representam uma tradiçao milenar e para muitos sua prática é um ato cultural, suas raízes são profundas, o que fortalece a prática cultural e dificulta a proibição, pois ademais de ser considerado um rito, também traz à tona questionamentos e aversões.

Considera-se que em decorrência de criação de leis de Proteção Animal e desejos de manutenção da prática das touradas, os povos deveriam entrar em um consenso e refletir sobre o que seria melhor para ambas intenções. Deveriam procurar por alternativas que visassem à adaptação e reformulação da tradição, em práticas que mantivessem o aspecto cultural e de proteção animal.

\subsection{A Criticidade, a Reflexão e o Humor na Charge}

Como já anunciam os documentos norteadores no que se refere ao ensino de Línguas Estrangeiras, Parâmetros Curriculares Nacionais (BRASIL, 1998), Diretrizes Curriculares da Educação Básica (BRASIL, 2008), e Orientações Curriculares para o Ensino Médio (BRASIL, 2006), o aluno deve ser levado à reflexão e à criticidade, uma vez constituído como parte integrante da sociedade. Como a charge corresponde a um gênero discursivo que se utiliza da imagem para criticar determinada atitude ou assunto que permeia a sociedade contemporânea, seus elementos pictóricos são imprescindíveis para o entendimento da temática que se estabelece no texto.

Sendo assim, e como já destacado, a charge em questão faz referência a uma prática espanhola, como pode ser comprovado pelas cores vermelho e amarelo que preenchem o fundo da imagem nas mesmas disposições das cores da bandeira da Espanha, bem como faz alusão a uma prática ainda comum e corriqueira em algumas regiões desta mesma nação. $\mathrm{O}$ traçado histórico exposto na discussão sobre o componente cultural possibilitou que se compreendesse melhor o que são e o que as touradas representam para o seu povo, como também, conhecer as origens e crenças dessa prática cultural, como foi possível visualizar nas colocações de Fuentes (2001) sobre a origem e história das touradas. Nesse sentido, pode-se dizer que o tema ou temática (conceito bakhtiniano) da charge corresponde às touradas.

Dado às características de estilo e quanto às formas composicionais, é possível verificar que a charge se desenvolve em um único quadro, tem os personagens simbólicos e a bandeira 
espanhola que se encontra disposta de maneira implícita, devido à disposição horizontal das cores vermelho e amarelo; traz uma crítica e faz referência às touradas e corridas de touros; faz uma sátira, gera reflexão; pode-se verificar a presença do humor, em um meio de circulação implícita à figura.

De acordo com as conceituações bakhtinianas, o estilo está tanto em relação ao escritor como para o gênero, ou seja, pode estar relacionado ao estilo do autor e/ou estilo do gênero. No caso da charge, comprova-se que a mesma, no caso da elencada para esta forma de refletir, está de acordo com o estilo do gênero, bem como, de acordo com a construção composicional que a engendra. Mesmo, que seja característica da charge a relação com a realidade, é compreensível que a mesma faça parte de um contexto histórico do passado, e que, hoje, represente um resgate desses fatos históricos e socioculturais.

Consiste em um resgate porque ainda desperta à atenção do interlocutor a um fato, acontecimento do cotidiano e, apesar de estar disponível em um livro didático de 2010, a crítica que faz, ainda, se encontra persistente hoje e chama à atenção do leitor para a sensação de satisfação e emoção, que alguns sujeitos sentem ao verem uma tourada. É claro que não se pode generalizar, visto que, assim como existem sujeitos que apreciam as touradas, também existem aquelas que não a apreciam, porém, se optam por participar e compor as plateias que lotam as praças de touros, certamente, é porque sentem algum prazer nesta prática sóciohistórica e cultural.

Nessa charge, é por meio da interlocução em espanhol dos dois touros, pai e filho, que o chargista torna evidente sua comoção e, ao dar voz aos animais, torna as imagens representativas, pois ao personificar os touros, possibilita que se eleve a figura do animal ao mesmo nível dos humanos, ou seja, ao dar vozes aos animais os equipara ao homem e faz com que sejam vistos de maneira mais humana e comovente. Este jogo de transferência de personagens consiste em uma maneira de mostrar como realmente as touradas são cruéis e desumanas, ao passo que demonstram uma escolha estilística do autor do texto, ou seja, corresponde a um desígnio próprio do estilo do chargista.

Uma possível tradução ao português da fala dos touros seria: "- Papai, por que as pessoas desfrutam enquanto nós morremos?"; “- Porque nós não morremos, nos matam.”. Observa-se que o chargista põe em evidência o prazer que as pessoas sentem ao ver o touro morrer pelas mãos do toureiro, o representante do povo, uma espécie de carrasco, bem como, o prazer que sentem as pessoas que perseguem o touro pelas ruas, atacando-o até a morte nas corridas de touros. Sendo assim, destaca-se que no ambiente escolar o professor deverá levar o seu aluno a refletir sobre a mensagem que a charge traz, possibilitando a este que reflita e desenvolva uma opinião com princípios éticos, embasados em fatores reais, sejam históricos, culturais, políticos ou pessoais, mas que venham a criticar construtivamente, contribuindo para avanços e melhoras nas condições tradicionais e culturais que ainda venham a ser praticadas, seja na sua nação ao na do outro. Fazendo também com que o ensino da Língua Espanhola se desenvolva de maneira mais efetiva e valorativa, em que a semelhança com a língua materna não conduza a pensamentos errôneos de que a língua estrangeira espanhola é fácil porque se fala o português, mas que os alunos percebam que além de semelhanças, existem diferenças, e assim como as outras, estas podem ser linguísticas e culturais.

\section{CONSIDERAÇÕES FINAIS}


Verificou-se que, como texto, a charge selecionada, corresponde a um gênero discursivo, tendo em vista que se satisfaz enquanto forma comunicativa adquirida por meio de situações mediadas pela interação verbal. Trata de uma situação construída socialmente e efetivada em práticas comunicativas cotidianas e diversificadas. No que diz respeito, ao estilo do gênero e à sua construção composicional, a charge de Martin Favelis corresponde ao gênero discursivo, uma vez que apresenta os elementos constitutivos do mesmo, como temática, criticidade, humor, imagem, um quadro, entre outros. Quanto ao estilo do escritor, podem-se verificar as escolhas referentes às cores e falas dos personagens, bem como, a personificação dos mesmos. Quanto ao tema está evidente que se refere à prática cultural das touradas e corridas de touros.

Compreende-se que temas polêmicos e que geram discussões positivas e reflexivas em sala de aula, são dados e componentes enunciativos riquíssimos para o ensino da cidadania e do respeito à cultura do outro. Contudo, é preciso que o professor esteja preparado para esta prática, pois a aluno deve ser levado à reflexão e à criticidade conscientes e construtivas, reconhecendo em si e na sua sociedade situações semelhantes às touradas ou corridas de touros, como as rinhas de galo e as brigas de cães que, ainda, ocorrem às escondidas, mesmo estando proibidas, ou ainda, como os rodeios, práticas comuns na sociedade contemporânea e que, de uma forma ou de outra, acabam maltratando os animais.

A temática da charge pode ser estendida a todos os animais que sofrem maltrato e não apenas aos touros que são mortos em ações cruéis e desumanas, mas também, aos cães que são abandonados, torturados, enterrados vivos e mortos sem qualquer tipo de escrúpulo por parte do ser humano, o único animal considerado por muitos como racional.O humor resultante da compreensão da crítica apresentada pela charge não deve ser a única reação do leitor que deve refletir e se conscientizar de que algo precisa e deve ser feito para mudar esta realidade e que ele, enquanto sujeito que vive em sociedade, procure fazer a diferença, pois mesmo que sua atitude pareça pequena, no final fará uma diferença enorme, uma vez que, ao educar-se a si mesmo se está contribuindo para conscientizar o seu próximo e este a outros e outros.

Observou-se também que por meio deste gênero discursivo analisado é possível trabalhar com a cultura e a história de um povo, e mesmo por ter relação com situações atuais, quando se trata de uma charge antiga seu valor discursivo não desmerece, ao contrário, se renova e fortalece. $\mathrm{O}$ fato de ser antiga, não impossibilita uma atitude responsiva de leitor, tendo em vista que, apesar de ter ou não relação com o contexto sócio-histórico e cultural atual, faz parte da história de um povo, de uma nação, de uma forma de dizer.

Acredita-se que a partir de dimensões históricas, sociais e culturais, inerente ao processo de ensino e de aprendizagem de língua espanhola, principalmente em regiões de fronteiras geográficas de hispano-falantes, desfazendo equívocos, rebatendo injustiças e, finalmente atendendo ao verdadeiro objetivo de se aprender língua que é inovar e transformar aquele que dela se apropria para manter intercâmbios neste mundo globalizado.

\section{REFERÊNCIAS}

ALTENHOFEN, Cléo. Política linguística, mitos e concepções linguísticas em áreas bilíngues de imigrantes (alemães) no Sul do Brasil. In RILI II (2003), I (3), p. 83-93. 
BAKHTIN, Mikhail. Os gêneros do discurso. In: . Estética da criação verbal. 3. ed. Trad. Maria Ermantina Galvão G. Pereira. São Paulo: Martins Fontes, 2000, p. 277-326.

Os gêneros do discurso. In: Estética da criação verbal. Tradução Paulo Bezerra. 4. ed. São Paulo: Martins Fontes, 2003.p. 261-269.

O problema do texto na linguística, na filologia e em outras ciências humanas. In: Estética da criação verbal. Tradução Paulo Bezerra. 4. ed. São Paulo: Martins Fontes, 2003.p. 307-335.

VOLOSHÍNOV, V. N. Discurso na vida, discurso na arte: sobre poética sociológica. (1926). Tradução de Carlos Alberto Faraco e Cristóvão Tezza. In: VOLOSHINOV, V. N. Freudismo. Trad. I. R. Tiotunik. New York: Academic Press, 1976. (Circulação para uso didático).

. VOLOSHÍNOV, V. N. Marxismo e filosofia da linguagem. Trad. Michel Lahud e Yara Frateschi Vieira. São Paulo: Martins Fontes, 2006.

BISÃO. Imagem. Disponível em: <www.google.com.br> Acesso em: 20 jun. 2013.

BRAIT, Beth. Estilo. In: . (Org.). Bakhtin: conceitos-chave. 5.ed. São Paulo: Contexto, 2013, p. 79-102.

BRASIL. Diretrizes Curriculares da Educação básica: Língua Estrangeira Moderna. Brasília: MEC, 2008.

BRASIL. Orientações curriculares para o ensino médio. Brasília: MEC, 2006.

BRASIL. Parâmetros curriculares nacionais: terceiro e quarto ciclos do ensino fundamental: língua estrangeira: Brasília: MEC/SEF, 1998.

BRASIL. Dispõe sobre o Ensino da Lingua Espanhola: Lei 11.161 de 05 de agosto de 2005. Disponível em <http://www.planalto.gov.br/ccivil_03/_Ato2004-2006/2005/Lei/L11161.htm> Acesso em 15 jul. 2013.

CASTRO, Antonilma S. A. et al. A dissertação no vestibular da UEFS: gênero ou tipo?. Disponível em: <http://linguagem.unisul.br/paginas/ensino/pos/linguagem/cd/port/21.pdf $>$. Acesso em: 13 maio 2009.

CATALÁ CARRASCO, Jorge. El cómic en la enseñanza del español como lengua extranjera. Disponível em: <http://www.uv.es/foroele/foro3/Catala_2007.pdf> Acesso em: 16 jun. 2012

FAVELIS, Martin. Charge. Disponível em <http://2.bd.blogspot.com> Acesso em 20 jul. 2011

Charge. In: MARTIN, Ivan. Síntesis: curso de lengua española: ensino médio. São Paulo: Ática, 2010, p. 75.

Blog. Disponível em: < http://www.martinfavelis.com/> Acesso em 07 nov. 2013.

FUENTES, Carlos. O espelho enterrado: reflexões sobre a Espanha e o Novo Mundo. Rio de Janeiro: Rocco, 2001.

HEYE, Jurgen; VANDRESSEN, Paulinho. Línguas em contato. In: CARDOSO, Suzana A. M; MOTA, Jacyra A; SILVA, Rosa V. M. e. (Org.). Quinhentos anos de história linguística no Brasil. Salvador: Secretaria da Cultura e turismo do Estado da Bahias, 2006, p. 382-411. 
KATO, Mary A. A natureza da linguagem escrita. In: . No mundo da escrita: uma perspectiva psicolinguística. 2. ed. São Paulo: Ática, 1987, p. 10-41.

LEFFA, Vilson J. Língua estrangeira hegemônica e solidariedade internacional. In: KARWOSKI, A. M.; BONI, V. de F. C. V. (Orgs.) Tendências contemporâneas no ensino de inglês. União da Vitória, PR: Kaygange, 2006, p. 10-25.

LESSA, David P. O gênero discursivo charge e sua aplicabilidade em sala de aula. In: Revista Travessias, n. $01, \quad$ p. 1-17. Disponível em: $<e-$ revista.unioeste.br/index.php/travessias/article/download/2803/2203 >> Acesso em 10 maio 2010 .

MACHADO, Irene. Gêneros discursivos. In: BRAIT, B. (Org.). Bakhtin: conceitos-chave. 4. ed. São Paulo: Contexto, 2008, p. 151-166.

MARCUSCHI, Luiz Antônio. Gêneros textuais: configuração, dinamicidade e circulação. In: KARWOSKI, A. M. et al. (Org.). Gêneros textuais: reflexões e ensino. Palmas e União da Vitória, PR: Kaygangue, 2005, p. 17-33.

Gêneros textuais: definição e funcionalidade. In: DIONISIO, A. P. et al. (Org.) Gêneros textuais \& ensino. 5. ed. Rio de janeiro: Lucerna, 2007, p. 19-36.

MARTIN, Ivan. Sintesis: curso de lengua española: ensino médio. São Paulo: Ática, 2010, p. 75.

PADILLA GARCÍA, Xose A. Las viñetas cómicas como recurso en la enseñanza de ELE. In Español con humor, Fundación Comillas, 2010, p. 3-20.

PENÍNSULA IBÉRICA. Imagem Disponível em: <www.google.com.br> Acceso em: 20 jun. 2013.

PRAÇA DE TOUROS. Disponível em <www.google.com.br> Acesso em: 20 jun. 2013.

RAJAGOPALAN, Kanavillil. O lugar do inglês no mundo globalizado. In: SILVA, K. A. (org.). Ensinar e aprender linguas na contemporaneidade: linhas e entrelinhas. Campinas, SP: Pontes, 2010, p. 21-24.

RODRIGUES, Rosângela H. Os gêneros do discurso na perspectiva dialógica da linguagem: a abordagem de Bakhtin. In: MEURER, J. L; BONINI, A.; MOTTA-ROTH, D. (Orgs.). Gêneros: teorias, métodos, debates. São Paulo: Parábola Editorial, 2005, p. 152-183.

ROMUALDO, Edson. Charge Jornalística: intertextualidade e polifonia. Maringá: Eduem, 2000.

SALVADOR, Alzenaide C. O; SANTOS, Luana. O ensino de espanhol na educação básica brasileira: uma retrospectiva histórica. 2011. Disponível em $<$ http://pt.scribd.com/doc/76302616/o-Ensino-de-Espanhol-Na-Educacao-Basica-BrasileiraUma-Retrospectiva-Historica> Acesso em 10 de jul. 2013.

SPINASSÉ, Karen P. O ensino de línguas em contextos multilíngues. In: MELLO, Heliana; ALTENHOFEN, Cléo V; RASO, Tammaso. (Org.). Os contatos linguísticos no Brasil. Belo Horizonte: Editora UFMG, 2011, p. 423-444.

TOURADAS. Disponível em <http://wikipedia.org/wiki/Tourad> Acesso em: 28 jun. 2013. 